This item was submitted to Loughborough's Research Repository by the author.

Items in Figshare are protected by copyright, with all rights reserved, unless otherwise indicated.

\title{
3D printing with moondust
}

PLEASE CITE THE PUBLISHED VERSION

http://dx.doi.org/10.1108/RPJ-02-2015-0022

\section{PUBLISHER}

(c) Emerald Group Publishing Ltd.

\section{VERSION}

AM (Accepted Manuscript)

\section{PUBLISHER STATEMENT}

This work is made available according to the conditions of the Creative Commons Attribution-NonCommercialNoDerivatives 4.0 International (CC BY-NC-ND 4.0) licence. Full details of this licence are available at: https://creativecommons.org/licenses/by-nc-nd/4.0/

\section{LICENCE}

CC BY-NC-ND 4.0

\section{REPOSITORY RECORD}

Goulas, Athanasios, and Ross Friel. 2019. "3D Printing with Moondust”. figshare.

https://hdl.handle.net/2134/18300. 


\title{
3D Printing with Moondust
}

\author{
Athanasios Goulas ${ }^{1}$, Ross J. Friel ${ }^{2}$ \\ 1,2 Wolfson School of Mechanical \& Manufacturing Engineering, \\ Loughborough University, Loughborough, Leicestershire, LE11 3TU, United Kingdom
}

\begin{abstract}
Purpose - The purpose of this paper is to investigate the effect of the main process parameters of Laser Melting (LM) type Additive Manufacturing (AM) on multi layered structures manufactured from JSC-1A Lunar regolith (Moondust) simulant powder.

Design/methodology/approach - Laser diffraction technology was used to analyse and confirm the simulant powder material particle sizes and distribution. Geometrical shapes were then manufactured on a Realizer SLM ${ }^{\mathrm{TM}} 100$ using the simulant powder. The laserprocessed samples were analysed via Scanning Electron Microscopy (SEM) to evaluate surface and internal morphologies, Energy-dispersive X-ray Spectroscopy (EDS) to analyse the chemical composition after processing and the samples were mechanically investigated via Vickers micro-hardness testing.

Findings - A combination of process parameters resulting in an energy density value of $1.011 \mathrm{~J} / \mathrm{mm}^{2}$ allowed the successful production of components directly from Lunar regolith simulant. An internal relative porosity of $40.8 \%$, material hardness of $670 \pm 11 \mathrm{HV}$ and a dimensional accuracy of $99.8 \%$ were observed in the fabricated samples.

Originality/value - This research paper is investigating the novel application of a Powder Bed Fusion AM process category as a potential on-site manufacturing approach for manufacturing structures/components out of Lunar regolith (Moondust). It was shown that this AM process category has the capability to directly manufacture multi-layered parts out of Lunar regolith, which has potential applicability to future moon colonization.
\end{abstract}




\section{INTRODUCTION}

Space exploration has been of global interest since the 1950's, especially after the first successful mission to send a human into orbit around the Earth in 1961 (Devezas et al., 2012). The latest programs from many of the major space agencies, such as the European Space Agency (ESA), are intending to send manned missions back into space (Hufenbach et al., 2014). A possible stepping stone for further manned and unmanned, exploration of the solar system could be via the establishment of a permanent Lunar facility. This facility could then act as a launch pad for vehicles destined for the further reaches of our star system. The benefits of launching from the Lunar surface would be: a lower energy requirement (i.e. less fuel needed) to escape the Lunar gravitational field compared to Earths; zero air resistance to launch vehicles (greater fuel efficiencies and/or higher attainable velocities), no atmospheric considerations (i.e. bad weather, high winds, etc.) and fewer issues with navigating the Earth orbiting objects and trash (i.e. satellites and debris). Of course achieving a permanent Lunar colony and using it as a construction and launch facility is a multifaceted significant engineering challenge. However one of the greatest hurdles is the severe cost and difficulty in transporting bulk building materials from the Earth's surface to the Lunar surface. It has been documented that for space applications ESA spends up to $10.000 €$ to transfer $1 \mathrm{~kg}$ of material into low earth orbit (Futron Corporation, 2002) - these costs would increase greatly if applied to transferring $1 \mathrm{~kg}$ from Earth to the Lunar surface.

A suggested way of reducing the mass of material required to be shipped is to use the existing bulk material of the Lunar surface as a construction material - Lunar regolith (Happel, 1993). Lunar regolith is the material defined as the first 4-15 m of Lunar 'soil' that has been derived by the fragmentation of the bedrock due to minor meteoritic impacts (Eckart, 2006). To best use this existing material in the most efficient way would require a 
flexible manufacturing system that would be able to operate in the Lunar environment, build 3D structures via a method that requires no further material additions and function in an autonomous fashion. An Additive Manufacturing (AM) (aka 3D Printing) system could potentially meet these requirements and allow the utilization of Lunar regolith for monolithic structures.

Previous research has investigated the use of the Directed Energy Deposition AM process category (Balla et al., 2010) and the Binder Jetting AM process category (Cesaretti et al., 2014) to manufacture objects with Lunar regolith simulant. These studies both showed the potential of AM for this application however the use of a Powder Bed Fusion (PBF) AM category could allow the use of the regolith as is and in situ (no need to mechanically blow the powder, include additional compounds or use materials and techniques unsuited to the actual Lunar environment). This study therefore aims to explore the use of a PBF category AM process (Laser Melting - Figure 1) to manufacture structures from Lunar regolith simulant. 


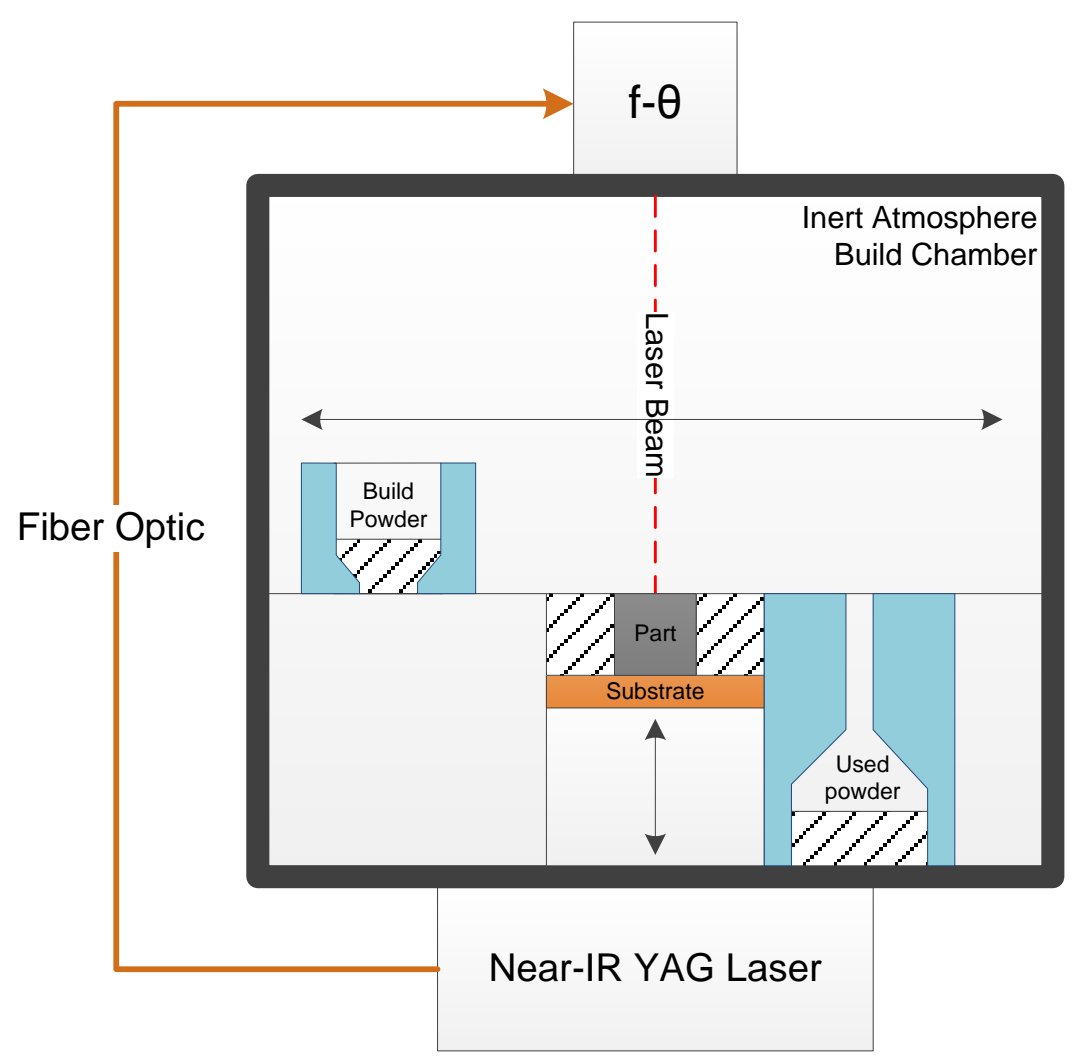

Figure 1 - Schematic of the Laser Melting, Powder Bed Fusion Additive Manufacturing process.

The major elemental compositions of the Lunar regolith are mostly silicate minerals. Studies have been published that analyse the basic aspects of both the actual and the simulant material; such as thermal optical properties (Gaier et al., 2011), glass properties (Ray et al., 2010) and also comparisons between the available Lunar regolith simulants (Liu and Taylor, 2011). However a minimal amount of publications exist regarding feasible methods for manufacturing physical assets through the use of Lunar regolith.

Balla et al. presented a direct fabrication method in a freeform environment using Laser Engineering Net Shaping (LENS ${ }^{\mathrm{TM}}$ ). The fabricated parts were characterized to evaluate the influence of laser processing on the microstructure, constituent phases and chemistry of the material (Balla et al., 2010). Despite the promising experimental results, this approach 
requires blowing of the powdered material via compressed air/nitrogen which making it problematic for implementation within the Lunar environment.

Cesaretti et al. by utilizing a full scale manufacturing method named D-Shape, proposed a 3D printing mechanism for the fabrication of one-off medium sized complete building structures, or building blocks, by extruding a regolith based concrete type material. The researchers in particular investigated the ability of this type of extruded material to "survive" under replicated Lunar environment conditions. Despite the potential feasibility this approached showed a major drawback of this attempt is the requirement for liquid water for the reticulation reactions to take place (Cesaretti et al., 2014).

Based on Lunar regolith' s propensity to absorbing microwave radiation, a modified printing head equipped with a microwave heating module was discussed by researchers Barmatz and Steinfeld, that could potentially directly fuse the regolith for building infrastructure and other In-situ Resource Utilization (ISRU) assets (Barmatz et al., 2014). This was shown to be a promising approach but requires multiple stages of processing in comparison with the relatively simple PBF approach.

A PBF approach, such as that proposed in this work, could utilise thermal power to fuse the indigenous material that exists on the moon. The thermal power needed for this purpose would not necessarily have to be provided by a laser source but could be provided from an alternative means, such as harnessing the thermal power from the sun through a system of lens and mirrors. Moreover a Lunar surface based PBF process would not require resources that are also extremely valuable to humans for survival such as water and from the material aspect a greater range of particle sizes could be utilised. 


\section{MATERIALS AND METHODS}

In this research paper, an experimental study using Laser Melting (LM) for processing Lunar regolith simulant is presented. The previous schematic (Figure 1) is a depiction of the LM process. Although LM is typically used for the fabrication of parts from metallic powders (Abe et al., 2001; Bertrand et al., 2007; Li et al., 2011;) this AM technique was identified as potentially being able to process the regolith ceramic material.

\subsection{Material}

For this research a commercially available Lunar regolith (Moondust) simulant under the name JSC-1A, supplied by Orbital Technologies Corporation, was used. The JSC-1A simulant can be summarized as crushed basalt, rich in glass and oxidized forms of Silicon, Aluminium, Iron, Calcium and Magnesium (Arslan et al., 2008). The simulant exhibited a composition that is very similar to actual Lunar 'soil' samples collected from the Lunar surface retrieved by the Apollo 14 mission; please refer to Table 1 . However the simulant does not replicate potential material characteristics that may occur as a result of 'space weathering' (meteoroid impacts, solar and cosmic radiation, etc.), within a hard vacuum environment. Published work suggests that this exposure may affect characteristics such as particle size, morphology, porosity and oxidative states of the mineral phases that exist in the material present on the lunar surface (Patrick et al., 2015). The weathering effects of the lunar soil are likely to vary widely and are impractical to simulate in an accurate manner therefore for this work the JSC-1A simulant represents as close an approximation as possible to genuine Lunar surface regolith. 
Table 1 - Composition (Wt\%) of the major constituents in the JSC-1A Lunar Regolith Simulant and comparison to Actual Lunar Regolith (Lunar Soil Sample 14163).

\begin{tabular}{lcc} 
Chemical Compound & $\begin{array}{c}\text { Lunar Regolith - } \\
\text { Simulant } \\
\text { (Orbitec, } 2005) .\end{array}$ & $\begin{array}{c}\text { Lunar Regolith - Actual (Sample } \\
14163) \\
\text { (Morries et al., 1983) }\end{array}$ \\
\hline Silicon Dioxide $\left(\mathrm{SiO}_{2}\right)$ & $46-49$ & 47.3 \\
Titanium Dioxide $\left(\mathrm{TiO}_{2}\right)$ & $1-2$ & 1.6 \\
Aluminum Oxide $\left(\mathrm{Al}_{2} \mathrm{O}_{3}\right)$ & $14.5-15.5$ & 15 \\
Ferric Oxide $\left(\mathrm{Fe}_{2} \mathrm{O}_{3}\right)$ & $3-4$ & 3.4 \\
Iron Oxide $(\mathrm{FeO})$ & $7-7.5$ & 7.4 \\
Magnesium Oxide $(\mathrm{MgO})$ & $8.5-9.5$ & 9 \\
Calcium Oxide $(\mathrm{CaO})$ & $10-11$ & 10.4 \\
Sodium Oxide $\left(\mathrm{Na}_{2} \mathrm{O}\right)$ & $2.5-3$ & 2.7 \\
Potassium Oxide $\left(\mathrm{K}_{2} \mathrm{O}\right)$ & $0.75-0.85$ & 0.8 \\
Manganese Oxide $(\mathrm{MnO})$ & $0.15-0.20$ & 0.2 \\
Chromium III Oxide $\left(\mathrm{Cr}_{2} \mathrm{O}_{3}\right)$ & $0.02-0.06$ & - \\
Diphosphorus Pentoxide & $0.6-0.7$ & 0.7 \\
$\left(\mathrm{P}_{2} \mathrm{O}_{5}\right)$ & & \\
\hline
\end{tabular}

To ensure compatibility with the LM technology used for this research the Lunar regolith simulant was screened with an industrial sieve manufactured by Retsch $\mathrm{GmbH}$ with apertures of $125 \mu \mathrm{m}$. To simulate the anhydrous nature of the Lunar surface the sieved powder was then dried in a Lenton WN60 laboratory oven at $100^{\circ} \mathrm{C}$ for 1 hour prior to laser processing. Preheating also helped better simulate the likely flow characteristics of the material through the hopper to the powder bed in an anhydrous situation (Lunar surface).

\subsection{Manufacturing Equipment}

LM experiments were conducted on a Realizer Selective Laser Melting (SLM) 100 machine. The SLM 100 is equipped with a continuous wave near infrared Ytterbium fibre laser (IPG Photonics Corp.) of a central emission range between $1.07-1.09 \mu \mathrm{m}$, with a standard TEMoo Gaussian beam profile and a maximum power output of $50 \mathrm{~W}$. The focusing element was a $120 \mathrm{~mm}$ F-theta lens where a beam between $30-300 \mu \mathrm{m}$ could be produced. 
Table 2 lists the range of parameters that were utilized during the experimental procedure. Samples were built on a mild steel substrate plate that was standard for the equipment and which was constantly heated at $200^{\circ} \mathrm{C}$.

Table 2 - SLM 100 machine parameters used during the experimental procedure.

\begin{tabular}{ll}
\hline Parameter & Value \\
\hline Laser & Near-IR Ytterbium Fibre Laser \\
Power $(\mathrm{W})$ & $10-50$ \\
Wavelength $(\mathrm{nm})$ & $1070-1090$ \\
Diameter of Laser Spot $(\mu \mathrm{m})$ & $100-300$ \\
Point Distance $(\mu \mathrm{m})$ & $20-300$ \\
Hatching Space $(\mu \mathrm{m})-($ Overlap \%) & $210-300(35 \%-0 \%)$ \\
Exposure Time $(\mu \mathrm{sec})$ & 1000 \\
Thickness of Powder Layer $(\mu \mathrm{m})$ & $100-350$ \\
Velocity $(\mathrm{m} / \mathrm{s})$ & Point Distance/Exposure Time \\
Environment & Argon Atmosphere \\
Temperature of substrate $\left({ }^{\circ} \mathrm{C}\right)$ & 200 \\
Substrate material & Mild steel with layer of regolith clad \\
\hline
\end{tabular}

\subsection{Analysis}

A Hitachi TM 3030 Scanning Electron Microscope (SEM) (Hitachi High-Technologies Europe $\mathrm{GmbH}$ ) equipped with Energy-dispersive X-ray Spectroscopy (EDS) was utilized for materials analysis. SEM was used for surface morphology, internal porosity and material microstructure analysis of the laser melted samples. EDS was used to analyse the chemical composition and distribution of the post laser melted samples.

The manufactured samples were prepared for SEM/EDS via a standard mounting, grinding and polishing regime on a Buehler AutoMet 250 (Buehler Inc., USA). They were mounted in a Buehler EpoxyCure 2 clear epoxy resin and ground using a SiC paper from P320 to P1200 grit size. Following grinding, polishing was carried out using a $6 \mu \mathrm{m}$ polishing cloth and diamond paste. Water was used as a cooling and lubricating liquid during the sample 
preparation. Prior to SEM, the samples were sputter coated using a Gold/Palladium alloy on a 40 seconds exposure time at $20 \mathrm{~mA}$ charge.

In order to quantify the relative porosity of the fabricated samples, SEM imaging of the crosssectioned samples was used. The acquired images were processed and binarized using a threshold value as shown in Figure 2. The relative porosity was calculated as a ratio of the black to white pixels which corresponded with the fraction of the surface voids over the total surface (Monroy et al., 2013).

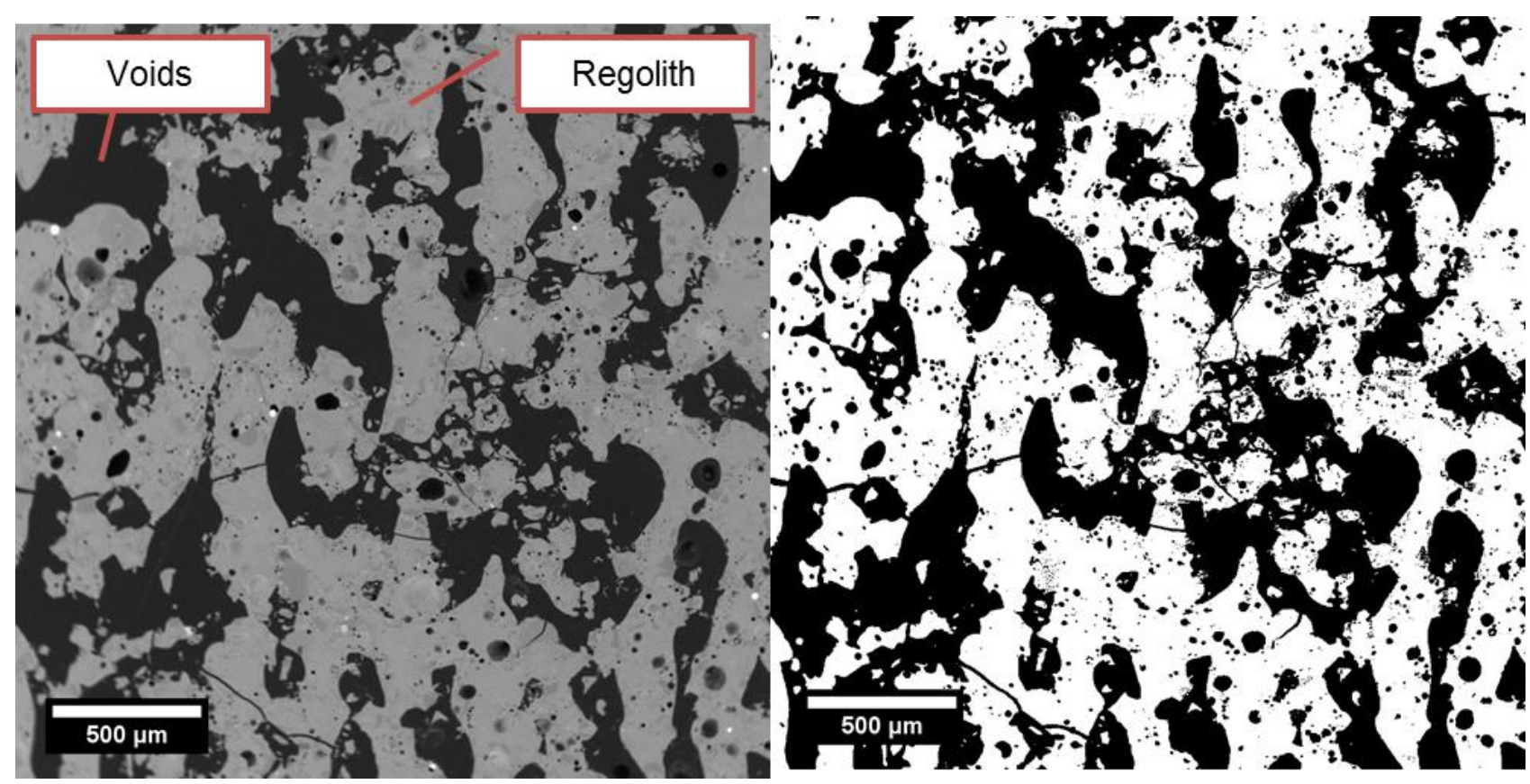

Figure 2 - Example binary processed SEM image.

The particle size and distribution of the sieved simulant was analysed and verified using a Mastersizer Sirocco 2000 laser diffraction particle analyser (Malvern Instruments Ltd.)

To test the hardness of the manufactured samples the Vickers micro-indentation method was used in accordance with the ASTM C1327 standard. Measurements were taken using a Buehler Micromet MMT-3 Vickers micro indenter (Buehler Inc., USA). The settings for the 
hardness testing were a $500 \mathrm{~g}(4.90 \mathrm{~N})$ load and a 15 seconds holding time. A set of 12 measurements for each sample were taken throughout the sintered material in order to acquire an accurate range of hardness values across the laser processed areas. 


\section{$3 \quad$ RESULTS AND DISCUSSION}

As previously mentioned, in order to ensure the compatibility of the LM technology with the Lunar regolith simulant, a process window between the particle size of the powder material, the diameter of the produced laser beam and the minimum layer thickness was identified in order to achieve a sufficient melt pool during laser processing and good packing behaviour of the powder during deposition of each new layer of the material. A Laser spot size of $\varnothing$ $300 \mu \mathrm{m}$, a minimum layer thickness of $150 \mu \mathrm{m}$ and a maximum material particle size of 125 $\mu \mathrm{m}$ were selected based on prior empirical data obtained by the authors.

Figure 3 shows a comparison between the as received regolith material and the sieved regolith. The particle size analysis of the as received material resulted in an average particle size of $321 \mu \mathrm{m}$ with particles up to $1.09 \mathrm{~mm}$, whereas the sieved sample resulted in an average particle size of $75 \mu \mathrm{m}$ with a maximum of $143 \mu \mathrm{m}$. The sieved material in comparison with the as received material exhibited better results in the follow on experiments.

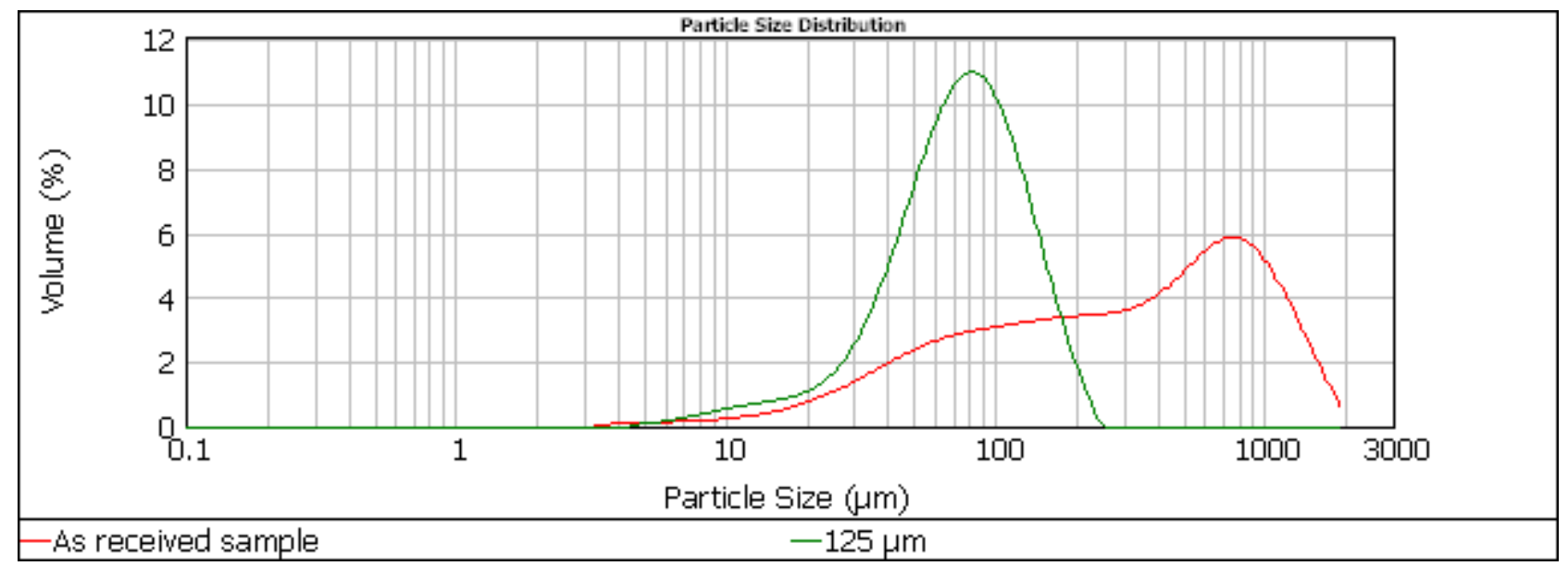

Figure 3-Difference between the as received and sieved regolith powder material.

198 experimental runs were performed with varying process parameters as listed in Table

2. Basic orthogonal shapes of $10 \times 10 \times 2 \mathrm{~mm}$ were modelled via CAD, prepared for processing via the machines native software and then arranged into a square array of 3 samples $\times 4$ 
samples, as shown in Figure 4. Complete melting of the regolith simulant material was observed with a laser power of 50W. Further laser energy increases led to the formation of an uncontrolled melt pool that conglomerated particles from outside the intended scanned track width causing an uncontrolled size increase in the scanned tracks and also led to curling of the sintered layer due to higher residual stresses that exist in the larger formed melt pool during the cooling down phase. Similar results were observed when reducing the laser scanning speed and the hatching space (distance between nearby scanned lines). Increasing the layer thickness of the newly deposited powder layer resulted in poor interlaminar bonding. This was because of inadequate penetration depth of the laser beam causing insufficient consolidation between layers.
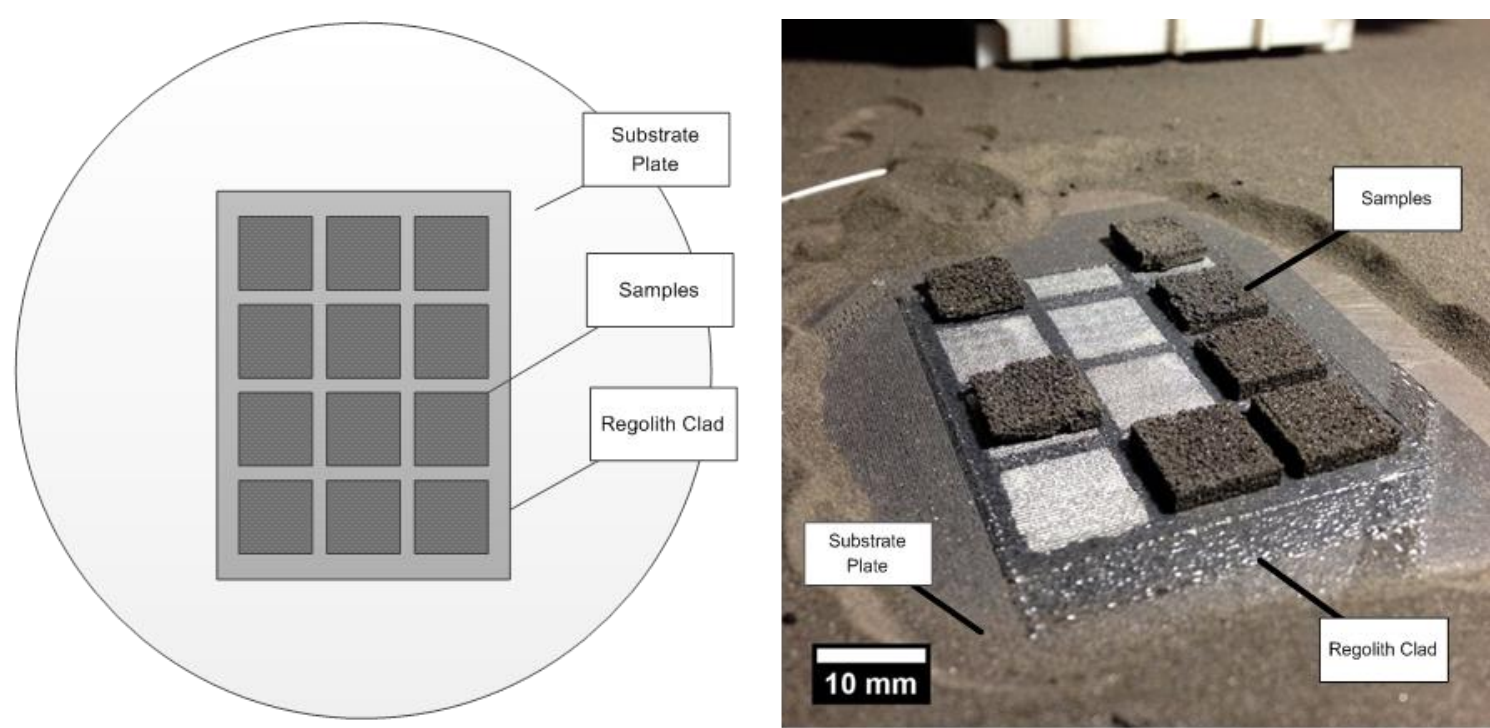

Figure 4 - Multi-Layer Laser Melted Additively Manufactured Lunar Regolith Simulant Samples.

A recurring issue during laser processing was that samples were continuously detaching from the mild steel substrate plate, after a few first layers were built. This was identified as being as a result of the inability of the molten ceramic material to create a bond with the metallic material of the substrate plate. This issue was overcome by using a proprietary method developed by the authors that is currently in the process of patenting. 
Process optimisation experiments resulted in the identification of a suitable process window (Table 3) that successfully allowed the production of geometries from the Lunar regolith simulant without any macroscopic irregularities or defects.

Table 3 - Experimentally determined process window for the SLM 100 using Lunar regolith simulant.

\begin{tabular}{ll}
\hline Parameter & Value \\
\hline Laser Power $(\mathrm{W})$ & $45-50$ \\
Scanning Speed $(\mathrm{mm} / \mathrm{sec})$ & $200-220$ \\
Layer Thickness $(\mu \mathrm{m})$ & $100-350$ \\
Beam Spot Size $(\mu \mathrm{m})$ & 300 \\
Hatching Space $(\mu \mathrm{m})($ Overlap \%) & $300(0 \%)-210(35 \%)$ \\
Energy Density $\left(\mathrm{J} / \mathrm{mm}^{2}\right)$ & $0.910-1.011$ \\
\hline
\end{tabular}

A combination of $50 \mathrm{~W}$ laser power, a scanning speed of $210 \mathrm{~mm} / \mathrm{sec}$, a laser beam spot size of $300 \mu \mathrm{m}$, with a $210 \mu \mathrm{m}$ hatching space ( $35 \%$ overlap) on a layer thickness of 150 $\mu \mathrm{m}$ resulted in an laser energy density of $1.011 \mathrm{~J} / \mathrm{mm}^{2}$, which gave out the most successful samples as shown in Figure 5.

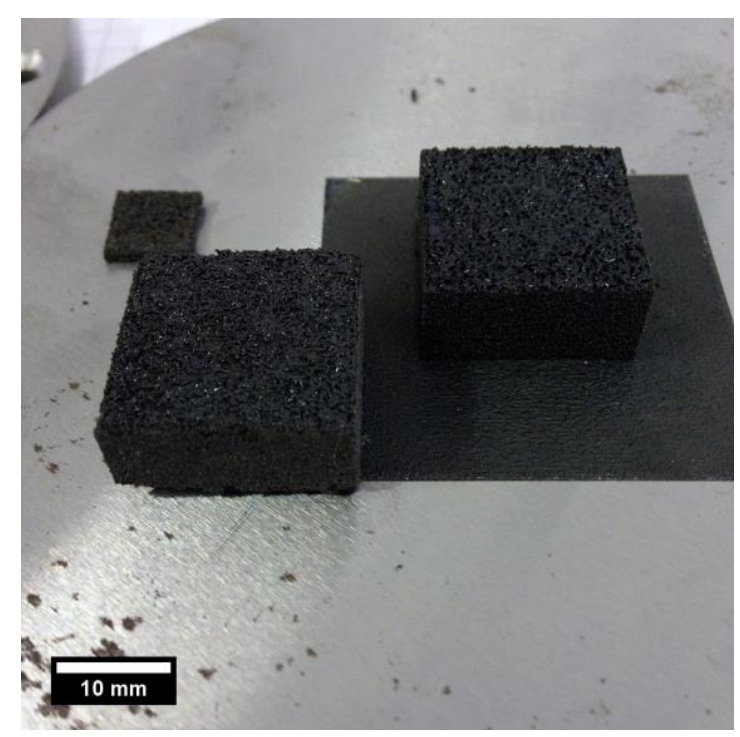

Figure 5-Various geometrical shapes manufactured using an energy density of 1.011 $\mathrm{J} / \mathrm{mm}^{2}$. 
Laser processing was conducted in a controlled inert environment of less than $2 \mathrm{ppb}$ of $\mathrm{O}_{2}$. It is known that residual $\mathrm{O}_{2}$ affects the optical (Tolochko et al., 2000) chemical and crystalline composition of a material when heating is taking place and in particular when the chemical reactions that alter the metal oxidation states $(\mathrm{Fe}, \mathrm{Ti})$ are promoted. By conducting laser processing in an inert environment (Argon in this case) or in vacuum, the partial pressure of $\mathrm{O}_{2}$ was reduced and would better simulate the conditions of the Lunar environment. This lower pressure would thermodynamically promote lower temperature reduction of metal oxides which in turn could improve laser melting and ensure that there would be no oxidation (Allan et al., 2013). As mentioned previously the mild steel substrate plate was also preheated to a temperature of $200^{\circ} \mathrm{C}$. By providing a steady and constant amount of heat from the substrate, the steep temperature difference $(\delta \mathrm{T} / \delta \mathrm{t})$ between the laser irradiation phase and the cooling down phase would be reduced. This would help reduce residual thermal stresses that would occur due to the thermally insulating nature (Balla et al., 2010) of the regolith due to it being a ceramic multi component material.

The layer thickness of $150 \mu \mathrm{m}$ was selected as a minimum layer thickness according to the measured maximum particle size of the material, and also to compensate for the relatively poor packing behaviour of the regolith particles in the powder bed due to their angular irregular shape, as shown in the SEM images in Figure 7. When the layer thickness of the deposited material was too thick and the process parameters could not be optimised accordingly, then sufficient melting could not occur and high levels of porosity would result (Averyanova et al., 2012).

The additively manufactured samples were successfully mounted and prepared for the SEM analysis. The SEM image in Figure 7 is an example cross-section of a sample depicting a substantial amount of melting between particles of the material in the same layer, despite some porosity. The authors suggest that the porosity was caused by a combination of factors: 
- Insufficient laser energy to provide sufficient consolidation between the scanned lines of the hatching pattern on the $\mathrm{X}-\mathrm{Y}$ plane (green arrow in Figure 7).

- Outgassing of the $\mathrm{K}_{2} \mathrm{O}, \mathrm{Na}_{2} \mathrm{O}$ and $\mathrm{MgO}$ oxides (red arrow in Figure 7) of the regolith material due to their relatively lower melting temperatures than some of the other ceramic material constituents.

- The size variance between the particles of the material which resulted in poor and uneven absorption of the laser energy input.

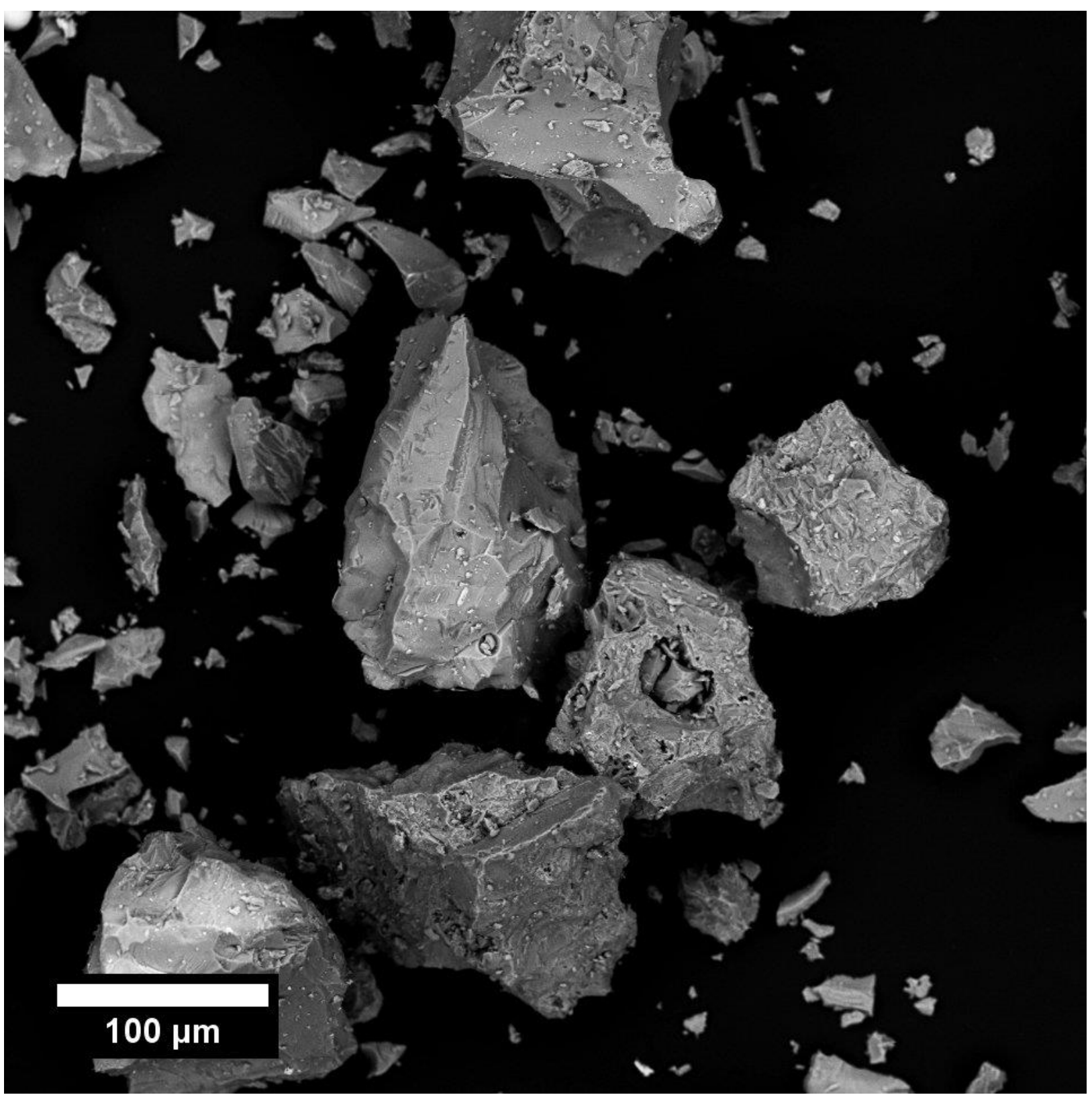

Figure 6 - SEM micrograph showing the angular shape of the JSC-1A. 


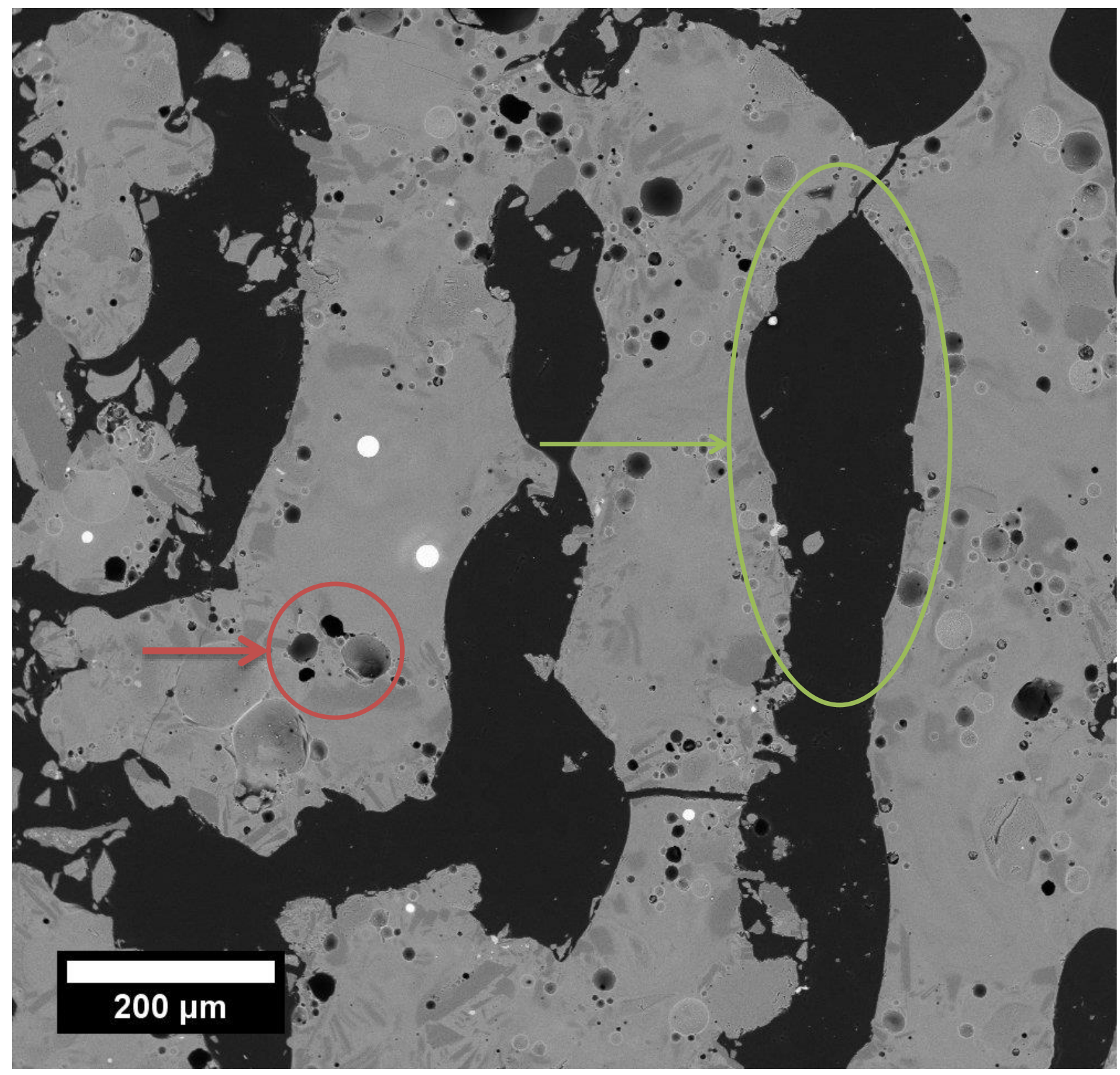

Figure 7-SEM image of a cross-sectioned sample in the $X-Y$ plane. 


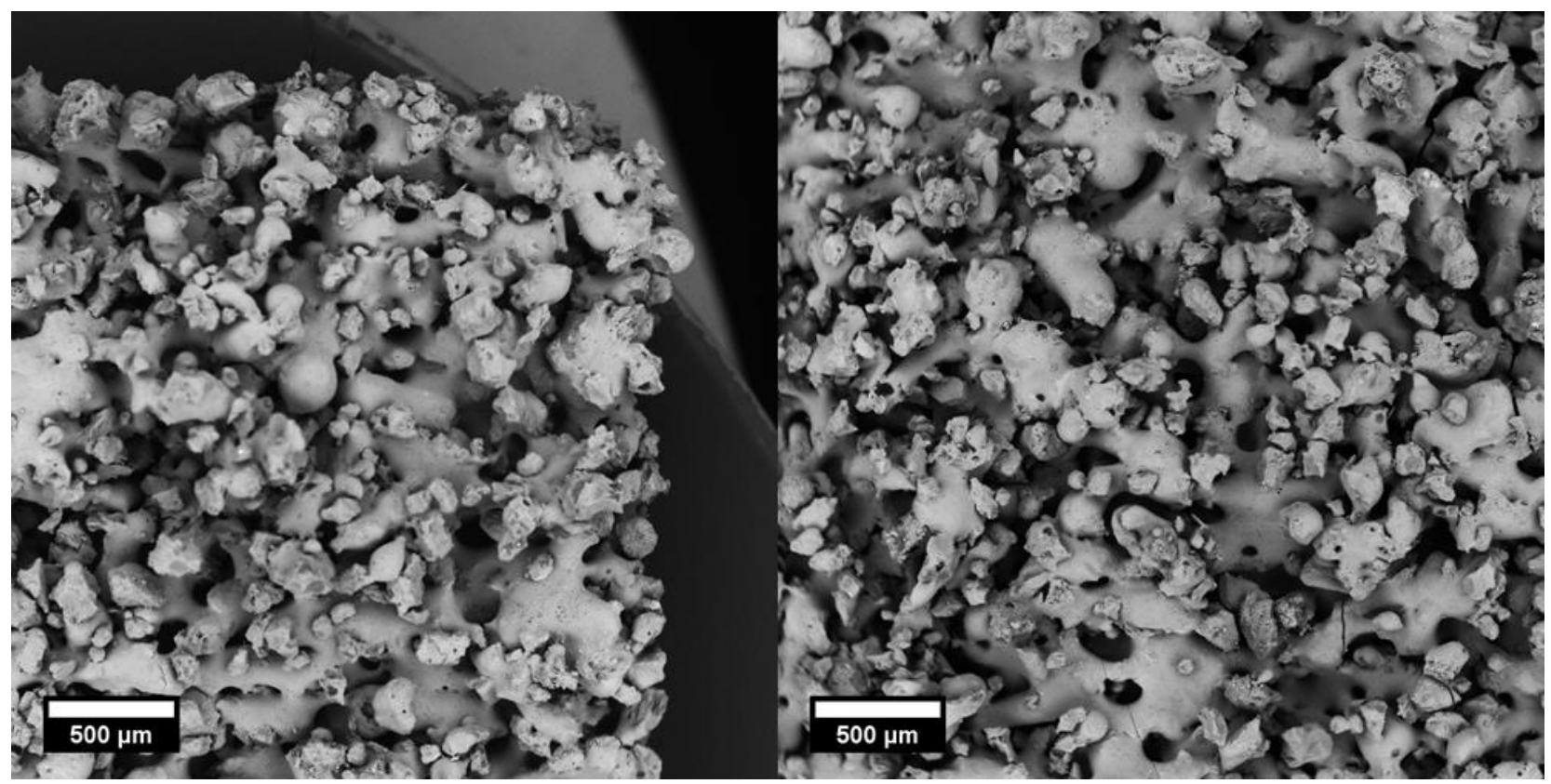

Figure 8-SEM images showing surface morphology of the fabricated samples.

Calculations from 10 different cross-sectioned sample SEM images through a software toolset revealed an average relative porosity value of $40.879 \pm 1.57 \%$.

The results of the Vickers micro hardness measurements revealed that the laser processed regolith samples exhibited a relatively high hardness of $670 \pm 11 \mathrm{HV}$, which was comparable to that of soda lime glass, $545 \pm 20 \mathrm{HV}$.

Table 4 shows a comparison between the average element concentrations of both the laser processed and the un-processed material that exist in the Lunar regolith simulant. Acquired data showed that the concentrations of Carbon, Magnesium, Aluminium, Silicon, and Chromium had increased as a result of the laser processing, whereas Oxygen, Sodium, Potassium, Calcium, Titanium and Iron had reduced. Previous research has shown that the high presence of Carbon is a result of contamination when specimens are exposed to the atmosphere after processing (Trigwell et al., 2009). 
The authors hypothesize that the increase of Silicon was due to the formation of glasses, based on the glass formation under rapid cooling rates (Ray et al., 2006) that can occur during laser processing. Also, based on similar results it is suggested that vaporisation due to the relatively low melting temperatures was the main reason for the decrease of Sodium $\left(883^{\circ} \mathrm{C}\right)$ and Potassium $\left(774^{\circ} \mathrm{C}\right)$. The remaining elements were inside the standard deviation of both processed and un-processed cases.

Table 4 - Elemental concentrations \% between processed (LM) and un-processed (RAW) regolith simulant acquired via EDS.

\begin{tabular}{rcccccccccccc}
\hline Element & $\mathrm{C}$ & $\mathrm{O}$ & $\mathrm{Na}$ & $\mathrm{Mg}$ & $\mathrm{Al}$ & $\mathrm{Si}$ & $\mathrm{K}$ & $\mathrm{Ca}$ & $\mathrm{Ti}$ & $\mathrm{Cr}$ & $\mathrm{Mn}$ & $\mathrm{Fe}$ \\
& & & & & & & & & & & & \\
\hline Processed & 10.14 & 32.64 & 1.82 & 3.50 & 8.69 & 23.47 & 0.67 & 7.74 & 1.33 & 0.35 & 0.315 & 9.48 \\
Material & \pm & \pm & \pm & \pm & \pm & \pm & \pm & \pm & \pm & \pm & \pm & \pm \\
& 0.76 & 0.25 & 0.05 & 0.23 & 0.40 & 0.28 & 0.06 & 0.17 & 0.07 & 0.141 & 0.06 & 0.46 \\
\hline Unprocessed & 0.344 & 45.49 & 1.99 & 1.83 & 7.20 & 15.84 & 0.77 & 8.43 & 1.62 & 0.11 & 0.31 & 16.49 \\
Material & \pm & \pm & \pm & \pm & \pm & \pm & \pm & \pm & \pm & \pm & \pm & \pm \\
& 0.01 & 1.59 & 0.06 & 0.17 & 0.61 & 0.75 & 0.07 & 0.59 & 0.19 & 0.03 & 0.06 & 2.51 \\
\hline
\end{tabular}




\section{CONCLUSIONS}

This study investigated the use of a Laser Melting Additive Manufacturing/3D Printing process as a potential solution for on-site Lunar manufacturing of 3D physical assets using Lunar regolith (moondust). This demonstration was performed using JSC-1A, a Lunar regolith simulant that resembles the actual elemental and chemical compound makeup of the real Lunar regolith samples that were acquired during the Apollo missions.

A range of experiments for optimisation of the process parameters resulted in successfully manufactured samples with a laser energy density of $1.011 \mathrm{~J} / \mathrm{mm}^{2}$ with settings of $50 \mathrm{~W}$ laser power, $210 \mathrm{~mm} / \mathrm{sec}$ scanning speed, $300 \mu \mathrm{m}$ laser beam spot size, $210 \mu \mathrm{m}$ hatching space (corresponds to $35 \%$ overlapping of the laser beam scan tracks) and a $150 \mu \mathrm{m}$ layer thickness. Manufactured samples had a relative porosity of $40.8 \%$ and exhibited good mechanical properties in terms of surface hardness with an average value of $670 \pm 11 \mathrm{HV}$. A change in the concentration of the constituents was present due to the thermo-physical reactions taking place during the laser melting and solidification phases.

The experimental approach documented in this article, presented the ability and the applicability of a PBF technique towards manufacturing physical assets out of non-traditional and multi-component ceramic materials.

Future work on the subject matter includes the further optimisation of the process parameters towards improving material density and hence material properties; as well as the formulation of a transferable manufacturing process model for building physical assets out of extra-terrestrial materials by using efficient and cost-effective thermal power. 


\section{REFERENCES}

Abe, F., Osakada, K., Shiomi, M., Uematsu, K. and Matsumoto, M. (2001), "The manufacturing of hard tools from metallic powders by selective laser melting", Journal of Materials Processing Technology, Vol. 111 No. 1-3, pp. 210-213.

Allan, S.M., Merritt, B.J., Griffin, B.F., Hintze, P.E. and Shulman, H.S. (2013), "HighTemperature Microwave Dielectric Properties and Processing of JSC-1AC Lunar Simulant", Journal of Aerospace Engineering, Vol. 26 No. 4, pp. 874-881.

Arslan, H., Sture, S. and Batiste, S. (2008), "Experimental simulation of tensile behavior of lunar soil simulant JSC-1", Materials Science and Engineering A, Vol. 478 No. 1-2, pp. 201-207.

Averyanova, M., Cicala, E., Bertrand, P. and Grevey, D. (2012), "Experimental design approach to optimize selective laser melting of martensitic 17-4 PH powder: part I single laser tracks and first layer", Rapid Prototyping Journal, Vol. 18 No. 1, pp. 2837.

Balla, V.K., Roberson, L.B., OConnor, G.W.O., Trigwell, S., Bose, S. and Bandyopadhyay, A. (2010), "First Demonstration on Direct Laser Fabrication of Lunar Regolith Parts", Rapid Prototyping Journal, Vol. 18 No. 6, pp. 451-457.

Barmatz, M., Steinfeld, D., Anderson, M. and Winterhalter, D. (2014), "3D Microwave Print Head Approach for Processing Lunar and Mars Regolith", 45th Lunar and Planetary Science Conference, pp. 3-4.

Bertrand, P., Goeuriot, P., Smurov, I., Combe, C. and Bayle, F. (2007), "Ceramic components manufacturing by selective laser sintering", Applied Surface Science, Vol. 254 No. 4, pp. 989-992.

Cesaretti, G., Dini, E., De Kestelier, X., Colla, V. and Pambaguian, L. (2014), "Building components for an outpost on the Lunar soil by means of a novel 3D printing technology", Acta Astronautica, Elsevier, Vol. 93, pp. 430-450.

Devezas, T., de Melo, F.C.L., Gregori, M.L., Salgado, M.C. V., Ribeiro, J.R. and Devezas, C.B.C. (2012), "The struggle for space: Past and future of the space race", Technological Forecasting and Social Change, Elsevier Inc., Vol. 79 No. 5, pp. 963985.

Eckart, P. (2006), The Lunar Base Handbook: An Introduction to Lunar Base Design (GNRL USE), Brown-Churchill Series, McGraw-Hill, available at: http://books.google.co.uk/books?id=mp7dnQEACAAJ.

Futron Corporation. (2002), "Space Transportation Costs: Trends in Price Per Pound to Orbit 1990-2000", Whitepaper.

Gaier, J.R., Ellis, S. and Hanks, N. (2011), "Thermal Optical Properties of Lunar Dust Simulants and Their Constituents", Journal of Thermophysics and Heat Transfer, Vol. 26 No. 4, pp. 573-580. 
Happel, J.A. (1993), "Indigenous Materials for Lunar Construction", Applied Mechanics Reviews, Vol. 46 No. 6, p. 313.

Hufenbach, B., Reiter, T. and Sourgens, E. (2014), "ESA strategic planning for space exploration", Space Policy, Elsevier Ltd, Vol. 30 No. 3, pp. 174-177.

Li, R., Shi, Y., Wang, L., Liu, J. and Wang, Z. (2011), "The key metallurgical features of selective laser melting of stainless steel powder for building metallic part", Powder Metallurgy and Metal Ceramics, Vol. 50 No. 3-4, pp. 141-150.

Liu, Y. and Taylor, L. a. (2011), "Characterization of lunar dust and a synopsis of available lunar simulants", Planetary and Space Science, Elsevier, Vol. 59, pp. 1769-1783.

Monroy, K., Delgado, J. and Ciurana, J. (2013), "Study of the pore formation on CoCrMo alloys by selective laser melting manufacturing process", Procedia Engineering, Elsevier B.V., Vol. 63, pp. 361-369.

Patrick, E.L., Mandt, K.E., Escobedo, S.M., Winters, G.S., Mitchell, J.N. and Teolis, B.D. (2015), "A qualitative study of the retention and release of volatile gases in JSC-1A lunar soil simulant at room temperature under ultrahigh vacuum (UHV) conditions", ICARUS, Elsevier Inc., doi:10.1016/j.icarus.2015.03.015.

Ray, C.S., Reis, S.T., Pontuschka, W.M., Yang, J.B., Sene, F.F., Giehl, J.M., Kim, C.W., et al. (2006), "Mossbauer and EPR spectra for glasses and glass-ceramics prepared from simulated compositions of Lunar and Martian soils", Journal of Non-Crystalline Solids, Vol. 352 No. 32-35, pp. 3677-3684.

Ray, C.S., Reis, S.T., Sen, S. and O'Dell, J.S. (2010), “JSC-1A lunar soil simulant: Characterization, glass formation, and selected glass properties", Journal of NonCrystalline Solids, Elsevier B.V., Vol. 356, pp. 2369-2374.

Tolochko, N.K., Khlopkov, Y. V., Mozzharov, S.E., Ignatiev, M.B., Laoui, T. and Titov, V.I. (2000), "Absorptance of powder materials suitable for laser sintering", Rapid Prototyping Journal, Vol. 6 No. 3, pp. 155-161.

Trigwell, S., Captain, J.G., Arens, E.E., Quinn, J.W. and Calle, C.I. (2009), "The use of tribocharging in the electrostatic beneficiation of lunar simulant", IEEE Transactions on Industry Applications, Vol. 45 No. 3, pp. 1060-1067. 